\title{
Increased expression of matrix metalloproteinase 3 can be attenuated by inhibition of microRNA-155 in cultured human astrocytes
}

Anatoly Korotkov ${ }^{1 \dagger}$, Diede W. M. Broekaart ${ }^{1 \dagger}$, Jackelien van Scheppingen ${ }^{1}$, Jasper J. Anink ${ }^{1}$, Johannes C. Baayen², Sander Idema ${ }^{2}$, Jan A. Gorter ${ }^{3}$, Eleonora Aronica ${ }^{1,4 \dagger}$ and Erwin A. van Vliet ${ }^{1,3^{*}+}$

\begin{abstract}
Background: Temporal lobe epilepsy (TLE) is a chronic neurological disease, in which about $30 \%$ of patients cannot be treated adequately with anti-epileptic drugs. Brain inflammation and remodeling of the extracellular matrix (ECM) seem to play a major role in TLE. Matrix metalloproteinases (MMPs) are proteolytic enzymes largely responsible for the remodeling of the ECM. The inhibition of MMPs has been suggested as a novel therapy for epilepsy; however, available MMP inhibitors lack specificity and cause serious side effects. We studied whether MMPs could be modulated via microRNAs (miRNAs). Several miRNAs mediate inflammatory responses in the brain, which are known to control MMP expression. The aim of this study was to investigate whether an increased expression of MMPs after interleukin-1 $\beta$ (IL13) stimulation can be attenuated by inhibition of the inflammation-associated miR-155.

Methods: We investigated the expression of MMP2, MMP3, MMP9, and MMP14 in cultured human fetal astrocytes after stimulation with the pro-inflammatory cytokine IL-1 $\beta$. The cells were transfected with miR-155 antagomiR, and the effect on MMP3 expression was investigated using real-time quantitative PCR and Western blotting. Furthermore, we characterized MMP3 and miR-155 expression in brain tissue of TLE patients with hippocampal sclerosis (TLE-HS) and during epileptogenesis in a rat TLE model.

Results: Inhibition of miR-155 by the antagomiR attenuated MMP3 overexpression after IL-1 $\beta$ stimulation in astrocytes. Increased expression of MMP3 and miR-155 was also evident in the hippocampus of TLE-HS patients and throughout epileptogenesis in the rat TLE model.

Conclusions: Our experiments showed that MMP3 is dynamically regulated by seizures as shown by increased expression in TLE tissue and during different phases of epileptogenesis in the rat TLE model. MMP3 can be induced by the pro-inflammatory cytokine IL-1 $\beta$ and is regulated by miR-155, suggesting a possible strategy to prevent epilepsy via reduction of inflammation.
\end{abstract}

Keywords: Epileptogenesis, Temporal lobe epilepsy, Extracellular matrix, MiRNA-155, MMP3

\footnotetext{
* Correspondence: e.a.vanvliet@uva.nl

${ }^{\dagger}$ Anatoly Korotkov, Diede W. M. Broekaart, Eleonora Aronica and Erwin A. van

Vliet contributed equally to this work.

'Department of (Neuro) Pathology, Amsterdam UMC, University of

Amsterdam, Meibergdreef 9, 1105 AZ Amsterdam, The Netherlands

${ }^{3}$ Swammerdam Institute for Life Sciences, Center for Neuroscience, University

of Amsterdam, Science Park 904, 1098 XH, Amsterdam, The Netherlands

Full list of author information is available at the end of the article
}

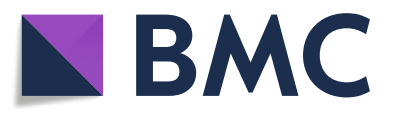

(c) The Author(s). 2018 Open Access This article is distributed under the terms of the Creative Commons Attribution 4.0 International License (http://creativecommons.org/licenses/by/4.0/), which permits unrestricted use, distribution, and reproduction in any medium, provided you give appropriate credit to the original author(s) and the source, provide a link to the Creative Commons license, and indicate if changes were made. The Creative Commons Public Domain Dedication waiver (http://creativecommons.org/publicdomain/zero/1.0/) applies to the data made available in this article, unless otherwise stated. 


\section{Background}

Epilepsy is a common neurological disease characterized by spontaneous recurrent seizures, affecting more than 50 million people worldwide. It is defined by any of the following conditions: (1) at least two unprovoked (or reflex) seizures occurring $>24 \mathrm{~h}$ apart. (2) One unprovoked (or reflex) seizure and a probability of further seizures similar to the general recurrence risk (at least 60\%) after two unprovoked seizures, occurring over the next 10 years. (3) Diagnosis of an epilepsy syndrome [1]. Temporal lobe epilepsy (TLE) is one of the most common forms of focal epilepsy in adults [2,3], which is frequently associated with hippocampal sclerosis [4]. The neuropathological processes associated with human TLE include neuronal loss, aberrant axonal growth and neurogenesis in the hippocampus, neuroinflammation, gliosis, reorganization of the extracellular matrix (ECM), and blood-brain barrier (BBB) dysfunction [5-9].

Matrix metalloproteinases (MMPs) constitute a class of proteases responsible for the remodeling of the ECM. Under normal physiological conditions various MMPs are involved in ECM homeostasis and synaptic plasticity in the brain [10-13]. Under pathological conditions, MMPs can be activated by a variety of stimuli including pro-inflammatory cytokines [14]. The pro-inflammatory cytokine IL-1 $\beta$ can be produced in the central nervous system (CNS) by activated astrocytes in response to tissue damage, increased neuronal activity or cellular stress [15-18]. Astrocytes contribute to chronic neuroinflammation in epilepsy not only as the major source of IL-1 $\beta$ [17], but also due to their role in $\mathrm{K}^{+}$buffering, uptake of extracellular glutamate, glutamine supply for presynaptic terminals [19] as well as the ability to control synaptogenesis [20]. The deregulation of MMP expression and activity has been also associated with TLE, where it may contribute to altered neuronal excitability, acute and chronic neuroinflammation, neurodegeneration, gliosis and a compromised BBB [14, 21-25]. In the electrical post-status epilepticus (SE) rat TLE model, a large-scale transcriptome study revealed that the expression of MMP2, MMP3, MMP9 and MMP14 in the brain was increased and dynamically regulated at different stages of epileptogenesis [26]. The role of MMP9 in epileptogenesis has been extensively studied in various animal models [22] with the focus on the modulation of synaptic plasticity associated with seizures [27]. MMP3 has also been implicated in neurodegenerative disorders [28-31] and shown to contribute to the increased BBB permeability and apoptosis [32, 33]. Increased expression of MMP3 expression was previously demonstrated in the hippocampus after kainic acid-induced seizures in mice [34] and after pilocarpine-induced status epilepticus in rats [35]. In summary, accumulating evidence indicates that increased expression and/or activity of MMPs after an insult can contribute to epileptogenesis. Therefore, reducing
MMP expression or activity has been suggested as a strategy for the prevention and/or modulation of epileptogenesis.

The increased gene expression under pathological conditions can be modulated by miRNAs. miRNAs are small non-coding RNAs capable of regulating target gene expression at post-transcriptional level [36-38]. miRNAs have been shown to be involved in the regulation of various biological processes within the CNS $[39,40]$ and have been implicated in neurological disorders, such as epilepsy [41, 42]. miRNAs can regulate gene expression directly through complementary binding to multiple messenger RNA (mRNA) transcripts and indirectly through modulating intracellular signaling pathways associated with the target genes. Several miRNAs have been shown to mediate inflammation in the brain [40]. This includes miR-146a, which inhibits inflammation in astrocytes [43-45]. Another inflammatory miRNA, miRNA-155, has also been shown to be expressed in astrocytes and been implicated in various CNS pathologies [46], including epilepsy [47-49]. Since the activation of MMP expression, especially MMP3 and MMP9, has been linked to pro-inflammatory signaling, miR-155 might modulate their expression through the regulation of inflammation. Indeed, miR-155 was previously demonstrated to be involved in the regulation of MMP3 under inflammatory conditions in synovial fibroblasts [50,51].

The aim of this study was to investigate whether increased MMP expression under inflammatory conditions can be attenuated by inhibition of miR-155. Therefore, we investigated MMP expression in cultured human fetal astrocytes after IL- $1 \beta$ stimulation and transfection with the antagomiR of miR-155. Furthermore, we characterized MMP and miR-155 expression in resected brain tissue of patients with TLE as well as during epileptogenesis in a rat TLE model.

\section{Methods \\ Cell cultures}

Primary fetal astrocyte-enriched cell cultures were derived from human fetal brain tissue (14-20 weeks of gestation) obtained from medically induced abortions. All material was collected from donors from whom a written informed consent for the use of the material for research purposes was obtained by the Bloemenhove clinic. Tissue was obtained in accordance with the Declaration of Helsinki and the Amsterdam UMC Research Code provided by the Medical Ethics Committee. Tissue samples were collected in DMEM/HAM F10 (1:1) medium (Gibco/ThermoFisher Scientific, Waltham, MA, USA), supplemented with $1 \%$ penicillin/streptomycin and 10\% fetal calf serum (FCS). Primary cell cultures of astrocytes were prepared as previously described [49]. The culture medium was subsequently refreshed twice a week. Cultures reached 
confluence after 2-3 weeks. Astrocytes were used for analyses at passages $2-5$. More than $98 \%$ of the cells in primary culture, as well as in the successive 12 passages were strongly immunoreactive for the astrocytic marker glial fibrillary acid protein (GFAP) and $S 100 \beta$ as previously reported [45].

\section{Transfection and stimulation of cell cultures}

Cells were plated in poly-L-lysine coated plates $\left(5 \times 10^{4}\right.$ cells/well in 12-well plates for RNA analysis or $2 \times 10^{5}$ cells/well in 6-well plates for protein analysis) and were transfected with miR-146a or miR-155 mimic pre-miRNA (mirVana miRNA mimics, Applied Biosystems, Carlsbad, CA, USA), or antisense locked nucleic acid (LNA) oligonucleotides against miR-155-5p (Ribotask ApS, Odense, Denmark). Oligonucleotides were delivered to the cells using Lipofectamine 2000 transfection reagent (Life Technologies, Grand Island, NY, USA) in a final concentration of $50 \mathrm{nM}$ for a total of $24 \mathrm{~h}$ before the stimulation of astrocytes. Astrocytic cultures were stimulated with human recombinant (r)IL-1 $(10 \mathrm{ng} / \mathrm{ml}$; Peprotech, Rocky Hill, NJ, USA) for $24 \mathrm{~h}$ (for RNA analysis) or for $48 \mathrm{~h}$ (for protein analysis) before harvesting the cells. Viability of human cell cultures was not influenced by the stimulation with IL-1 $\beta$, as shown previously [52].

\section{Human brain tissue}

The cases included in this study were obtained from the archives of the department of (Neuro)Pathology of the Amsterdam UMC, Amsterdam, The Netherlands. A total of 16 brain specimens were examined from patients undergoing surgery for drug resistant TLE. Tissue was obtained and used in accordance with the Declaration of Helsinki and the Research Code provided by the Medical Ethics Committee. All cases were reviewed independently by two neuropathologists, and the classification of hippocampal sclerosis was based on analysis of microscopic examination as described by the International League Against Epilepsy (HS type 1, $n=12$; HS type 2, $n=4$ ) [53]. Control material was obtained during autopsy of people without a history of seizures or other neurological diseases $(n=10)$. Brain tissue was fixed in $10 \%$ buffered formalin and embedded in paraffin.

\section{Experimental animals}

Adult male Sprague-Dawley rats (Harlan Netherlands, Horst, The Netherlands) were used in this study which was approved by the University Animal Welfare committee. The rats were housed individually in a controlled environment $\left(21 \pm 1{ }^{\circ} \mathrm{C}\right.$; humidity $60 \%$; lights on 08:00 AM-8:00 PM; food and water available ad libitum).
Electrode implantation and status epilepticus induction Rats were anesthetized with an intramuscular injection of ketamine (74 mg/kg; Alfasan, Woerden, The Netherlands) and xylazine (11 mg/kg; Bayer AG, Leverkusen, Germany), and were placed in a stereotactic frame. In order to record hippocampal EEG, a pair of insulated stainless steel electrodes (70 $\mu \mathrm{m}$ wire diameter, tips $800 \mu \mathrm{m}$ apart) was implanted into the left dentate gyrus (DG) under electrophysiological control, as described previously [54]. A pair of stimulation electrodes was implanted in the angular bundle. Two weeks after recovery from the operation, each rat was transferred to a recording cage $(40 \times$ $40 \times 80 \mathrm{~cm})$ and connected to a recording and stimulation system (NeuroData Digital Stimulator, Cygnus Technology Inc., Delaware Water Gap, PA, USA) with a shielded multi-strand cable and electrical swivel (Air Precision, Le Plessis Robinson, France). A week after habituation to the new condition, rats underwent tetanic stimulation $(50 \mathrm{~Hz})$ of the hippocampus in the form of a succession of trains of pulses every $13 \mathrm{~s}$. Each train was of $10 \mathrm{~s}$ duration and consisted of biphasic pulses (pulse duration $0.5 \mathrm{~ms}$, maximal intensity $700 \mu \mathrm{A}$ ). Stimulation was stopped when the rats displayed sustained forelimb clonus and salivation for several minutes, which usually occurred within $1 \mathrm{~h}$.

\section{EEG monitoring}

To determine seizure frequency, continuous EEG recordings $(24 \mathrm{~h}$ /day) were made in all rats. Hippocampal EEG signals were amplified $(10 \times)$ via a field effect transistor that connected the headset to an amplifier (20x; CyberAmp, Axon Instruments, Burlingame, CA, USA), band-pass filtered $(1-60 \mathrm{~Hz})$ and digitized by a computer. A seizure detection program (Harmonie, Stellate Systems, Montreal, Canada) sampled the incoming signal at a frequency of $200 \mathrm{~Hz}$ per channel. All EEG recordings were visually screened and seizures were confirmed by trained human observers. Seizures were characterized by synchronized high-voltage amplitude oscillations and were scored when the amplitude increased more than 2-fold and lasted for at least $10 \mathrm{~s}$.

\section{Tissue preparation}

For in situ hybridization, rats were deeply anesthetized with pentobarbital (Euthasol, AST Farma, Oudenwater, The Netherlands, $60 \mathrm{mg} / \mathrm{kg}$ i.p.) and perfused via the ascending aorta $\left(300 \mathrm{ml} 0.37 \% \mathrm{Na}_{2} \mathrm{~S} / 300 \mathrm{ml} 4 \%\right.$ paraformaldehyde in $0.1 \mathrm{M}$ phosphate buffer, $\mathrm{pH} 7.4$ ). Rats were perfused at three different time points after SE, each corresponding to the phases of epileptogenesis: the acute phase ( 1 day post-SE, $n=5$ ), the latent phase ( 1 week post-SE, absence of electrographic seizures, $n=3$ ), and the chronic phase (3-4 months post-SE, recurrent spontaneous electrographic seizures are evident, $n=6$ ) [55]. Control rats $(n=4)$ that were implanted with EEG electrodes 
but not stimulated were also included. The brains were post-fixated overnight, dissected and paraffin embedded. Tissue was sectioned at $6 \mu \mathrm{m}$ and mounted on pre-coated glass slides (Star Frost, Waldemar Knittel, Braunschweig, Germany).

For RT-qPCR analysis, rats were decapitated 1 day after SE (acute phase, $n=5$ ), 1 week after SE (latent phase, $n=$ 6) or 3-4 months after SE (chronic phase, $n=5$ ). Control rats $(n=10)$ included young rats $(n=5)$ and age-matched controls for the chronic stage $(n=5)$. The brain was dissected and the parahippocampal cortex (PHC), which includes mainly the entorhinal cortex and parts of the perirhinal and posterior piriform cortex, was removed by incision at the ventro-caudal part underneath the rhinal fissure until approximately $5 \mathrm{~mm}$ posterior to bregma, as well as the hippocampus. The hippocampus was sliced into smaller parts $(200-300 \mu \mathrm{m})$ and the DG and Cornu Ammonis (CA1) regions were cut out of the slices in $4{ }^{\circ} \mathrm{C}$ saline solution under a dissection microscope. All material was frozen on dry ice and stored at $-80^{\circ} \mathrm{C}$ until use.

\section{RNA isolation and real-time quantitative PCR analysis}

For RNA isolation, cell cultures, frozen human brain tissue, or frozen rat brain tissue were homogenized in $700 \mu \mathrm{l}$ Qiazol Lysis Reagent (Qiagen Benelux, Venlo, The Netherlands). Total RNA, including small RNAs, was isolated using the miRNeasy Mini kit (Qiagen Benelux, Venlo, The Netherlands) according to manufacturer's instructions. The concentration and purity of RNA were determined using a Nanodrop 2000 spectrophotometer (Thermo Fisher Scientific, Wilmington, DE, USA). To evaluate mRNA expression, $250 \mathrm{ng}$ of cell culture-derived total RNA was reverse-transcribed into cDNA using oligo $\mathrm{dT}$ primers. The primers used for the study are listed in (Additional file 1: Table S1). The geometric mean of elongation factor $1 \alpha(\mathrm{EF} 1 \alpha)$ and chromosome 1 open reading frame 43 (C1orf43) expression levels was used for the normalization of RT-qPCR in human tissue and cell cultures; the geometric mean of glyceraldehyde 3-phosphate dehydrogenase (GAPDH) and TATA-box-binding protein (TBP) expression levels was used for the normalization of RT-qPCR in rat tissue. The PCR mix and cycling conditions were used as previously described [56].

The expression of miR-155-5p and U6B small nuclear RNA (RNU6B) was analyzed using TaqMan microRNA assays (Applied Biosystems, Foster City, CA, USA). cDNA was generated using TaqMan MicroRNA reverse transcription kit (Applied Biosystems, Foster City, CA, USA) according to the manufacturer's instructions. The PCRs were run on the Roche LightCycler 480 (Roche Applied Science, Basel, Switzerland) with a 384-multiwell format.

Quantification of data was performed using LinRegPCR in which the baseline correction and window-of-linearity are determined for each sample separately, followed by a linear regression analysis on the Log (fluorescence) per cycle to fit a straight line through the PCR data set. The slope of this line is used to determine the PCR efficiency of each individual sample. The mean PCR efficiency per amplicon and the $\mathrm{Ct}$ value per sample are used to calculate a starting concentration N0 per sample, which is expressed in arbitrary fluorescence units $[57,58]$. The starting concentration N0 of each specific product was then divided by the geometric mean of the starting concentrations N0 of the reference genes, and this ratio was compared between groups. This value was further normalized to the corresponding control condition. The control condition used for RT-qPCR experiments in primary cultures was the condition stimulated by IL-1 $\beta$ due to undetectable/very low expression of MMP3 and MMP9 in untreated control.

\section{Western blot analysis}

Cells were harvested at $48 \mathrm{~h}$ after treatment. The cells were washed with ice-cold PBS and homogenized in ice-cold lysis buffer (50 mM Tris- $\mathrm{HCl} \mathrm{pH} \mathrm{7.4,} 150 \mathrm{mM}$ of $\mathrm{NaCl}, 1 \% \mathrm{NP}-40,0.5 \%$ sodium deoxycholate) supplemented with protease inhibitor (EDTA-free protease mixture inhibitor and phosphatase inhibitor (Roche Diagnostics, Almere, the Netherlands)) by incubating on ice for $10 \mathrm{~min}$ and collected using a cell scraper. The homogenates were centrifuged at $12,000 \mathrm{x} g$ for $10 \mathrm{~min}$ and the supernatant was used for further analysis. Protein content was determined using the bicinchoninic acid method [59]. Equal amounts of proteins $(5 \mu \mathrm{g} /$ lane for culture samples or $20 \mu \mathrm{g} /$ lane for tissue samples) were separated using sodium dodecylsulfate-polyacrylamide gel electrophoresis (SDS-PAGE). Subsequently, separated proteins were transferred onto polyvinylidene difluoride membranes (Immobilon-P; Merck, Darmstadt, Germany) for $90 \mathrm{~min}$ at $100 \mathrm{~V}$, using a wet electroblotting system (BioRad, Hercules, CA, USA). Blots were blocked for $1 \mathrm{~h}$ in $5 \%$ non-fat dry milk in Tris-buffered saline-Tween (TBS-T; $20 \mathrm{mM}$ Tris, $150 \mathrm{mM} \mathrm{NaCl}, 0.1 \%$ Tween 20, pH 7.5). Blots were incubated overnight with primary antibodies anti-MMP3 (1:200 mouse monoclonal, clone SL-1 IIIC4, EMD Millipore, Temecula, CA, USA) or anti- $\beta$-actin (1:50,000 monoclonal mouse, clone C4, Merck, Darmstadt, Germany). After several washes in TBS-T/ 5\% non-fat dry milk, blots were incubated with secondary antibodies goat anti-mouse IgG2b (for MMP3) or goat anti-mouse IgG1 coupled to horseradish peroxidase (both 1:2500; Dako, Glostrup, Denmark) for $1 \mathrm{~h}$. After several washes in TBS-T, immunoreactivity was visualized using ECL PLUS Western blotting detection reagent (GE Healthcare Europe, Diegen, Belgium). Expression of $\beta$-actin was used as loading control. Chemiluminescent signal was detected using ImageQuant LAS 4000 analyzer 
(GE Healthcare, Eindhoven, the Netherlands). Precision Plus Protein Dual Color Standards (Bio-Rad, Richmond, CA, USA) was used to determine the molecular weight of the proteins. For the quantitative analysis of the blots and in-situ micrographs the band intensities were measured densitometrically using ImageJ software (U.S. National Institutes of Health, Bethesda, MD, USA).

\section{In situ hybridization on human and rat brain tissue}

Paraffin-embedded brain tissue was deparaffinized in xylene and rinsed in ethanol $(2 \times 100 \%, 70 \%)$ and sterile water. Antigen retrieval was performed using a pressure cooker in sodium citrate buffer, $\mathrm{pH} 6.0$, at $121{ }^{\circ} \mathrm{C}$ for $10 \mathrm{~min}$. The oligonucleotide probe for miR-155 (Additional file 1) contained LNA modification, 2-o-methyl modification and digoxygenin (DIG) label (RiboTask ApS, Odense, Denmark). Sections were incubated with the probe (1:750 dilution) in hybridization mix $(600 \mathrm{mM} \mathrm{NaCl}, 10 \mathrm{mM}$ HEPES, 1 mM EDTA, 5x Denhardts, 50\% Formamide) for $1 \mathrm{~h}$ at $56{ }^{\circ} \mathrm{C}$. Sections were washed with saline-sodium citrate for $2 \mathrm{~min}, 0.5 \mathrm{x}$ for $2 \mathrm{~min}, 0.2 \mathrm{x}$ for $1 \mathrm{~min}$ (in agitation). After washing with sterile PBS, sections were blocked for 15 min with $1 \%$ BSA, $0.02 \%$ Tween 20 and $1 \%$ normal goat serum. Hybridization was detected with alkaline phosphatase (AP) labeled with anti-DIG (Roche Applied Science, Basel, Switzerland). Nitro-blue tetrazolium chloride (NBT)/5-bromo-4-chloro-3-indolyl phosphate p-toluidine salt (BCIP) was used as chromogenic substrate for AP (1:50 diluted in NTM-T buffer $(100 \mathrm{mM}$ Tris, $\mathrm{pH}$ 9.5; $100 \mathrm{mM} \mathrm{NaCl} ; 50 \mathrm{mM} \mathrm{MgCl}$; $0.05 \%$ Tween 20)). Negative control assays were performed without probes (sections were blank).

For double-staining, the sections were first processed for in situ hybridization, followed by immunohistochemistry. Slides were washed with PBS and incubated for $1 \mathrm{~h}$ at room temperature with primary antibodies in PBS; mouse anti-GFAP (1:4000, Sigma-Aldrich, St. Louis, MO, USA), mouse anti-NeuN (1:2000, MAB377, Chemicon, Temecula, CA, USA), mouse anti-CD34 (1:600, Immunotech, Monrovia, CA, USA) and mouse anti-CR3/43 (1:100, Agilent, Santa Clara, CA, USA) or rabbit anti-IBA-1 (1:2000, Wako Chemicals, Neuss, Germany). After washing with PBS, sections were stained with a polymer-based peroxidase immunohistochemistry detection kit (Brightvision plus kit, ImmunoLogic, Duiven, The Netherlands) according to the manufacturer's instructions. Signal was detected using the chromogen 3-amino-9-ethylcarbazole (Sigma-Aldrich, St. Louis, MO, USA).

\section{Evaluation of in situ hybridization}

Expression of miR-155 was quantitatively analyzed in the DG and CA1 of human brain tissue and in the DG, CA1 and entorhinal cortex of rat brain tissue by measuring the optical density using ImageJ. Since the quantitative analysis does not discriminate between different cell types, a semi-quantitative analysis was also performed in which miR-155 expression was assessed in neurons, cells with glial morphology and blood vessels. The intensity of the staining was evaluated using a scale of 1-4 (1: no; 2: weak; 3: moderate; 4: strong staining). The score represents the predominant cell staining intensity found in each case. Additionally, the relative number of positive cells ( 0 : no; 1 : single to $10 \%$; 2 : $11-50 \%$; 3 : > 50\%) was also evaluated. The in situ reactivity score (IRS) was calculated by multiplying the intensity score by the relative number score. The analysis was performed by two researchers that were blinded to group assignments.

\section{Statistical analysis}

Statistical analyses were performed using IBM SPSS Statistics 21. Comparisons between multiple groups were done using the Kruskal-Wallis test, Mann-Whitney $U$ test was used to compare two groups. A value of $p<0.05$ was assumed to indicate significant difference.

\section{Results \\ MMP expression in human fetal astrocytes after IL-1 $\beta$ stimulation}

Constitutively, MMP2 and MMP14 were expressed highly in primary cultures of human fetal astrocytes, whereas for MMP3 and MMP9 a low expression was observed (Additional file 2). RT-qPCR analysis demonstrated that gene expression of MMP3 and MMP9 was increased following IL- $1 \beta$ stimulation $(p<0.001$, Fig. 1a), and the induction was especially prominent for MMP3. Gene expression of MMP2 and MMP14 did not change. Immunocytochemistry (Fig. 1b) and Western blot analysis $(p<0.001$, Fig. $1 c, d)$ showed that MMP3 protein was also increased following IL-1 $\beta$ stimulation.

\section{Modulation of MMP3 expression in human fetal astrocytes by miRNA-155 after IL-1 $\beta$ stimulation}

Since MMP3 gene and protein expression was increased in human fetal astrocytes after IL-1 $\beta$ stimulation, we investigated whether MMP3 expression could be modulated. Therefore, human fetal astrocytes were transfected with miR-146a mimic, miR-155 mimic or miR-155 antagomiR and treated with IL-1 $\beta$. TaqMan RT-qPCR analysis confirmed that miR-155 was increased after IL-1 $\beta$ stimulation ( $p<0.001$; Additional file 3$)$, while transfection with miR-155 antagomiR did not alter miRNA levels, as previously shown [49]. Western blot analysis showed that inhibition of miR-155 by antagomiR resulted in a decreased MMP3 expression $(p<0.05)$ when compared to IL-1 $\beta$-stimulated condition (Fig. 1c, d), while miR-146a did not reduce MMP3 protein expression (data not shown). In contrast, overexpression of 


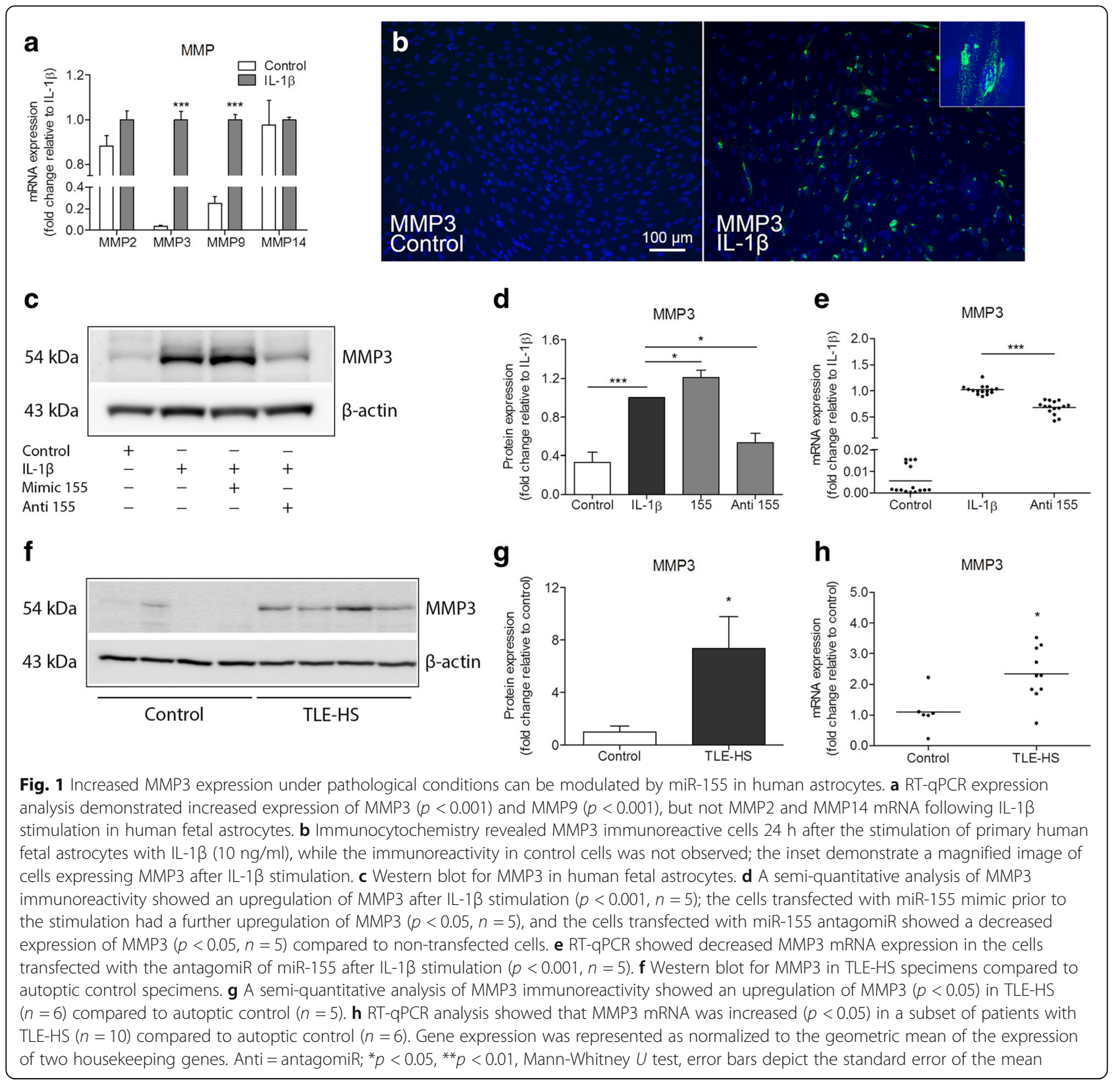

miR-155 led to a further increase $(p<0.05)$ of MMP3 protein expression after IL-1 $\beta$ stimulation (Fig. 1c, d). RT-qPCR analysis showed that MMP3 mRNA was also decreased in astrocytes transfected with miR-155 antagomiR $(p<0.001)$ as compared to non-transfected cells under IL-1 $\beta$ stimulation (Fig. 1e; Additional file 4).

MMP3 expression in the hippocampus of TLE-HS patients Following the findings in human astrocytic cell cultures, we investigated the expression of MMP3 in the hippocampal specimens resected from TLE-HS patients. The clinical features of the human subjects included in this study are summarized in Table 1 . Western blot analysis showed a weak MMP3 immunoreactivity in autopsy control samples, while MMP3 expression was more evident in TLE-HS specimens (Fig. 1f, g). Similarly, RT-qPCR analysis showed an increased MMP3 mRNA expression $(p<0.05)$ in the TLE-HS group as compared to controls (Fig. 1h).

\section{miR-155 expression in the hippocampus of TLE-HS patients}

We investigated the expression of miR-155 in the human hippocampus. TaqMan RT-qPCR analysis revealed an increased expression of miR-155 $(p<0.001)$ in the TLE-HS compared to controls (Fig. 2a). The cellular distribution of 
Table 1 Clinical findings of human samples used for RT-qPCR and in situ hybridization

\begin{tabular}{lllllllll}
\hline Experiment & Pathology & $n$ & Age & Gender m/f & $\begin{array}{l}\text { HS ILAE* } \\
\text { Type 1/type 2 }\end{array}$ & Duration of epilepsy (years) & $\begin{array}{c}\text { Age at onset } \\
\text { Number of seizures } \\
\text { (per month) }\end{array}$ \\
\hline RT-qPCR & Control & 6 & $63(25-86)$ & $4 / 2$ & - & - & - & - \\
& TLE-HS & 16 & $35(24-49)$ & $9 / 7$ & $12 / 4$ & $20(5-41)$ & $15(3-34)$ & $19(1-36)$ \\
ISH & Control & 5 & $48(31-64)$ & $3 / 2$ & - & - & - & - \\
& TLE-HS & 10 & $35(24-49)$ & $7 / 3$ & $7 / 3$ & $20(5-41)$ & $16(3-34)$ & $13(2-32)$ \\
\hline
\end{tabular}

TLE temporal lobe epilepsy, HS hippocampal sclerosis, ISH in situ hybridization, $m$ male, $f$ female. Values are given as mean (minimum-maximum)

*According to Blümcke et al. 2013 [53]

miR-155 was investigated by in situ hybridization in the DG and CA1. In autopsy control tissue, a moderate expression of miR-155 was observed in neurons, while a weak expression was found in cells with glial morphology (Fig. 2b, c). In TLE-HS, a moderate to strong miR-155 expression was observed in both neurons and cells with glial morphology (Fig. 2d, e). In order to confirm the observations of cell morphology, we performed a double immuno-labelling of miR-155 with the markers for different cell types. miR-155 was co-localized with the markers for neurons (NeuN), astrocytes (GFAP), microglia (CR3/43), and endothelial cells (CD34) in TLE-HS tissue (Fig. 2d, insets a, b; Fig. 2e, insets c, d). Quantitative analysis (Additional file 5) of miR-155 expression showed a trend toward increased miR-155 expression in the DG in TLE-HS tissue as compared to control. Since this analysis does not discriminate between different cell types, we also performed a semi-quantitative analysis (see the "Methods" section for description) which showed that the miR-155 IRS was increased for neurons (DG $p<0.05$, CA1 $p<0.01$ ), cells with glial morphology (DG, CA1 $p<0.01$ ), as well as for blood vessels (DG, CA1 $p<0.05$ ) compared to controls (Fig. 2f, g, h; Table 2).

\section{MMP3 expression during epileptogenesis in a rat TLE model}

We further investigated MMP3 expression in the brain of rats after SE. RT-qPCR analysis showed that MMP3 was increased in the DG 1 day and 3-4 months after SE induction (respectively, acute and chronic stages; $p<0.05$; Fig. 3a); increased expression was also seen during the acute stage $(p<0.01)$ in the CA1 region (Fig. $3 \mathrm{~b})$ and during all 3 stages of epileptogenesis (acute $p<0.01$; latent $p<0.01$; chronic $p<0.05$ ) in the PHC (Fig. 3c) of the rats.

\section{miR-155 expression during epileptogenesis in a rat TLE model}

We investigated the expression of miR-155 at different time points during epileptogenesis in the rat brain after SE. miR-155 expression was increased in the DG, CA1, and PHC during the acute $(p<0.001)$, latent $(p<0.001)$, and chronic $(p<0.01)$ phases as compared to control (Fig. 3d-f). miR-155 expression peaked at the acute phase in all three regions, but was also increased during the latent and chronic phases as compared to control.

The cellular distribution of miR-155 was investigated by in situ hybridization. A weak expression of miR-155 was observed in neurons in control rat hippocampus (Fig. 4a-c). Strong miR-155 expression was observed in the DG, CA1, and entorhinal cortex (EC) already at the acute phase following SE (Fig. 4d-f) and was also moderate to strong throughout the course of epileptogenesis at the latent (Fig. 4g-i) and chronic phases (Fig. 4j-l). Double labelling showed that miR-155 was expressed in neurons, astrocytes, and microglia (Fig. 4d insets a, b; Fig. 4e, inset c). In addition, miR-155 immunoreactivity was visible in blood vessels (Fig. 4e, inset d). Quantitative (Additional file 6) as well as semi-quantitative analysis confirmed an increased expression of miR-155 in neurons, cells with glial morphology, and blood vessels in the hippocampus during the acute, latent, and chronic phases (Fig. 5a-c; Table 3).

\section{Discussion}

We demonstrated that MMP3 expression was increased in primary cultures of human fetal astrocytes following stimulation of the cells with the pro-inflammatory cytokine IL-1 $\beta$. Inhibition of miR-155 attenuated the increased expression of MMP3 after the IL-1 $\beta$ stimulation. Increased expression of both MMP3 and miR-155 was also evident in the hippocampus of TLE-HS patients and throughout epileptogenesis in rats. These results are further discussed in detail in the following paragraphs.

\section{miR-155 modulates MMP3 in human astrocytes}

MMPs are key proteases participating in the remodeling of the ECM. We reported previously that the expression of MMP2, MMP3, MMP9, and MMP14 was increased and dynamically regulated in the brain of rats at different stages of post-SE epileptogenesis [26]. We have investigated the expression of these genes further in a primary culture of human astrocytes. Various stimuli, such as cytokines, growth factors, reactive oxygen species, or cellECM interactions are known to be responsible for the transcriptional activation of MMPs [33, 60-62]. In our experiments, the stimulation of human astrocytes with the pro-inflammatory cytokine IL-1 $\beta$ resulted in increased 

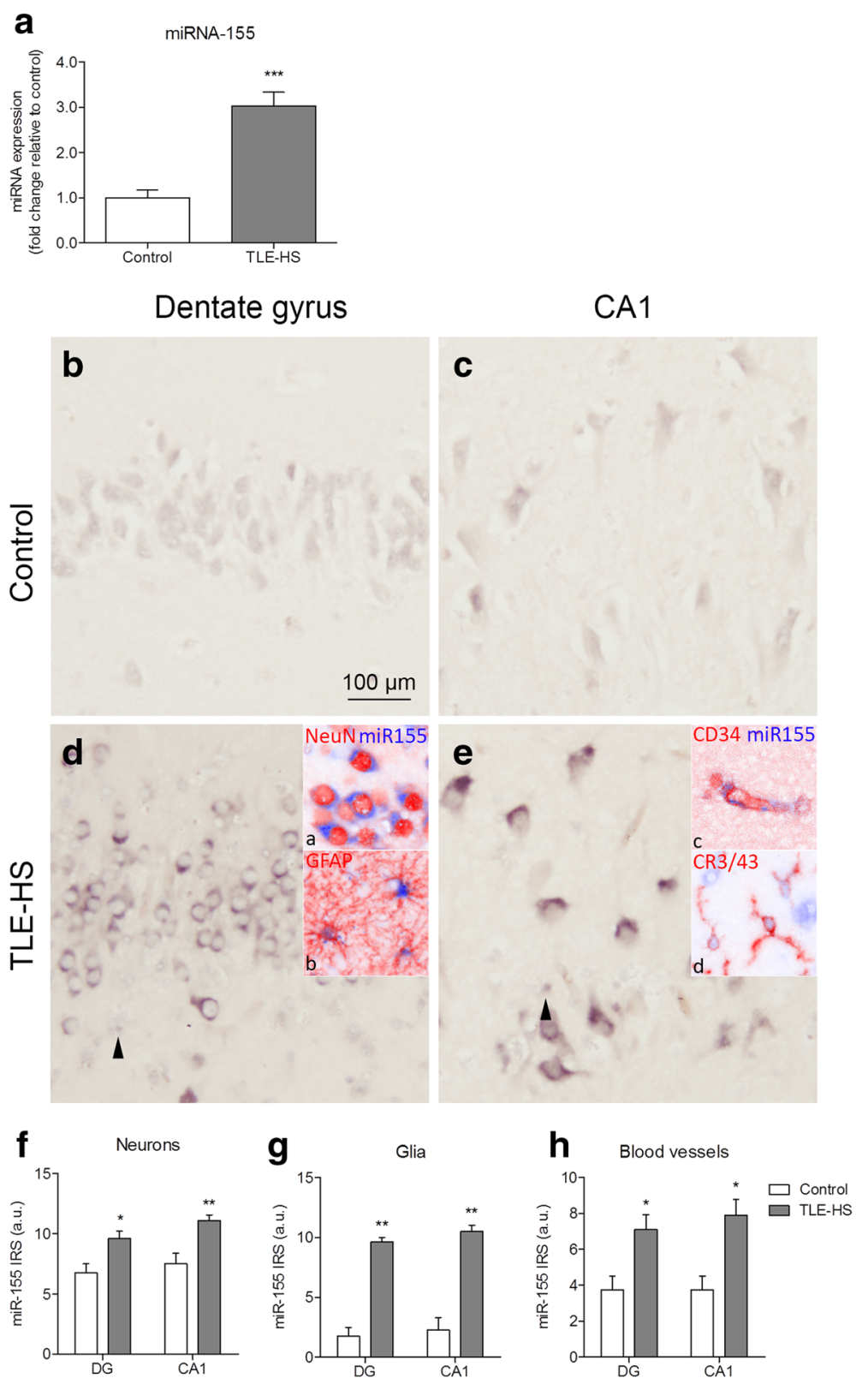

Fig. 2 miR-155 expression in TLE-HS. a miR-155 expression was increased in TLE-HS patients relative to controls evaluated by TaqMan RT-qPCR $(p<0.001)$. b-e In situ hybridization for miR-155 in the human hippocampus. A moderate neuronal miR-155 expression was observed in the control hippocampus (b, c). d, e miR-155 expression was increased in both neurons and in cells with glial morphology compared to control; co-localization was found with neurons (NeuN; d, inset a), astrocytes (GFAP; $\mathbf{d}$, inset b), endothelial cells (CD34; e, inset c) and microglia (CR3/43; e, inset d). Arrowheads indicate cells with glial morphology. f-h A semi-quantitative analysis of miR-155 IRS in neurons, cells with glial morphology, and blood vessels. Scale bar $100 \mu$ m; $^{*} p<0.05,{ }^{* *} p<0.01,{ }^{* * *} p<0.001$, Mann-Whitney $U$ test, error bars depict standard error of the mean

Table 2 In situ reactivity scores of miR-155 in the human hippocampus

\begin{tabular}{|c|c|c|c|c|c|c|}
\hline & \multicolumn{3}{|l|}{ DG } & \multicolumn{3}{|l|}{ CA1 } \\
\hline & Neurons & Glia & Vessels & Neurons & Glia & Vessels \\
\hline Control & $6(6-9)$ & $1(1-4)$ & $3(3-6)$ & $7.5(6-9)$ & $2.5(0-4)$ & $3(3-6)$ \\
\hline TLE-HS & $9(6-12)^{*}$ & $9(9-12)^{* *}$ & $6(4-12)^{*}$ & $12(9-12)^{* *}$ & $10.5(9-12)^{* *}$ & $9(4-12)^{*}$ \\
\hline
\end{tabular}

miR-155 in situ reactivity scores are given as median (minimum-maximum). This score was defined as intensity score (1 no; 2 weak; 3 moderate; 4 strong immunoreactivity) multiplied by relative number score $(0$ no; 1 single to $10 \% ; 211-50 \% ; 3>50 \%) ;{ }^{*} p<0.05,{ }^{* *} p<0.01$ 


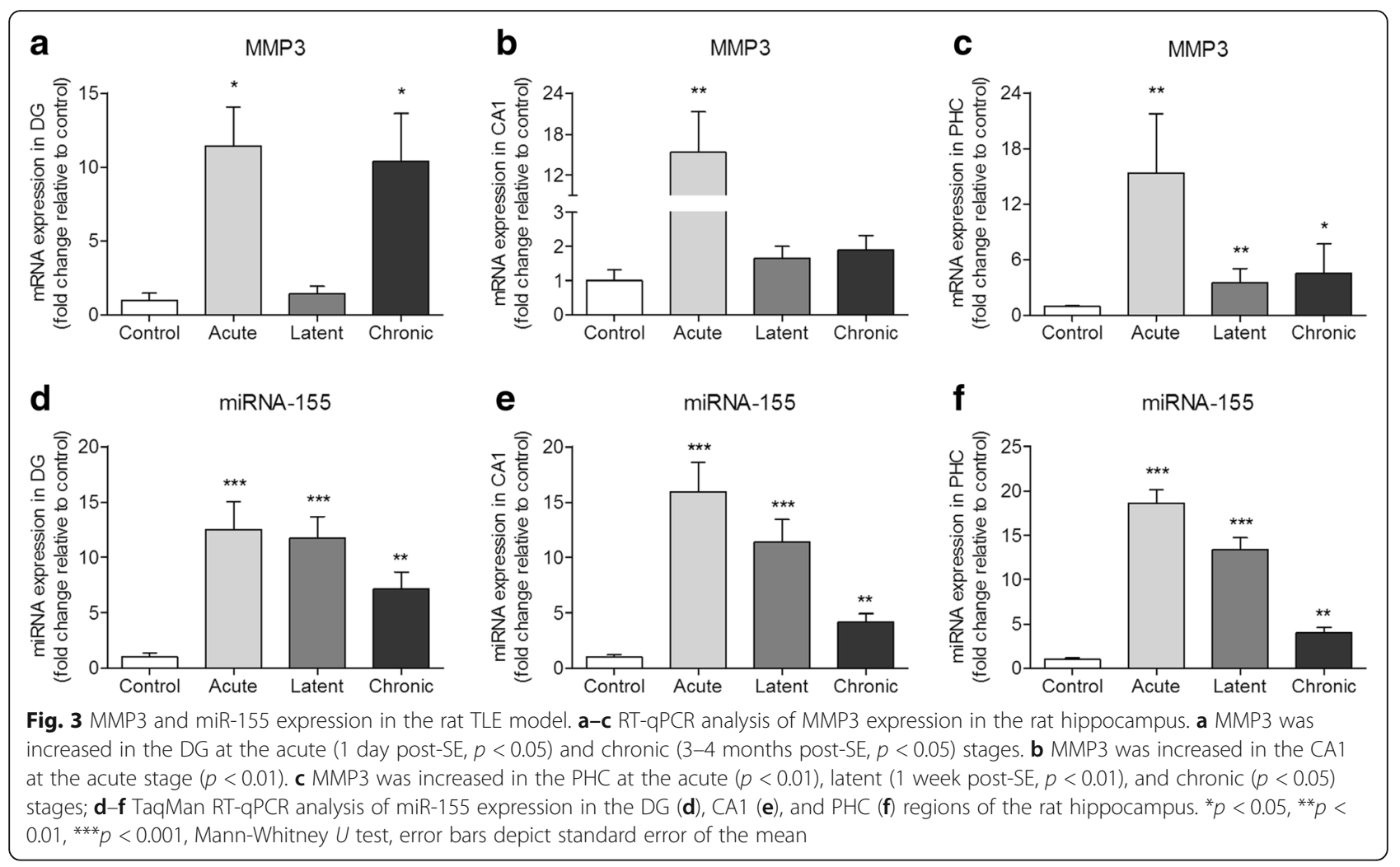

expression of MMP3. We further demonstrated that the increased expression of MMP3 after IL-1 $\beta$ stimulation was attenuated upon inhibition of miR-155 expression in the astrocytes by antagomiR transfection. To our knowledge, MMP3 has not been predicted or shown to be a direct target of miR-155, suggesting an indirect mechanism of miR-155-mediated inhibition of MMP3. The upregulation of MMP3 following pro-inflammatory stimuli has been previously reported, and it was proposed to be dependent on the activation of activator protein 1 (AP-1) and nuclear factor kappa-light-chain-enhancer of activated $B$ cells $(\mathrm{NF}-\mathrm{kB})$ transcription factors [32, 63-65]. These transcription factors have been associated with apoptosis, innate immune response, and inflammation [66, 67]. miR-155 production has been shown to be involved in the feedback regulation of these pathways $[68,69]$ and been attributed a bidirectional role in the regulation of pro-inflammatory signaling $[43,70,71]$. Therefore, it is likely that the inhibition of miR-155 exerts its effect on MMP3 expression via interference with the members of pro-inflammatory signaling pathways.

\section{Increased expression of MMP3 in TLE-HS and during epileptogenesis in a rat TLE model}

We found that MMP3 expression was increased in the hippocampus of TLE-HS patients. In healthy CNS, the expression of MMP3 is low, but it can be increased in pathology, such as ischemia, trauma, or neurodegenerative disorders [72-75]. TLE-HS is characterized by extensive neurodegeneration in the hippocampus, chronic neuroinflammation, reactive gliosis, remodeling of the ECM, and dysfunction of the BBB [54, 76-80]. Reactive astrocytes and microglia provide a major source of pro-inflammatory molecules, including IL-1 $\beta$ [81-85], and as discussed in the previous paragraph, astrocytes can produce increased amounts of MMP3 upon exposure to IL-1 $\beta$. Thus, the upregulation of MMP3 may be due to excessive production and release of pro-inflammatory cytokines and chronic neuroinflammation in TLE-HS.

Human TLE-HS tissue represents the end-stage of the disease and does not allow to track changes along the course of epileptogenesis. To further characterize the spatio-temporal changes of MMP3 expression, we used a rat model of post-SE epileptogenesis, which recapitulates the pathological features of TLE-HS [55]. The expression of MMP3 in the rat hippocampus was the highest during the acute phase of epileptogenesis, indicating the involvement of this protease shortly after an epileptogenic insult. Moreover, increased MMP3 expression was also observed in the DG and PHC during the chronic stage, which supports the observations made in human chronic TLE-HS specimens. MMP3 has been associated with neuroinflammation via its ability to activate microglial cells (causing them to produce superoxide, TNF-a, and IL-1 $\beta$ ) and participation in BBB 


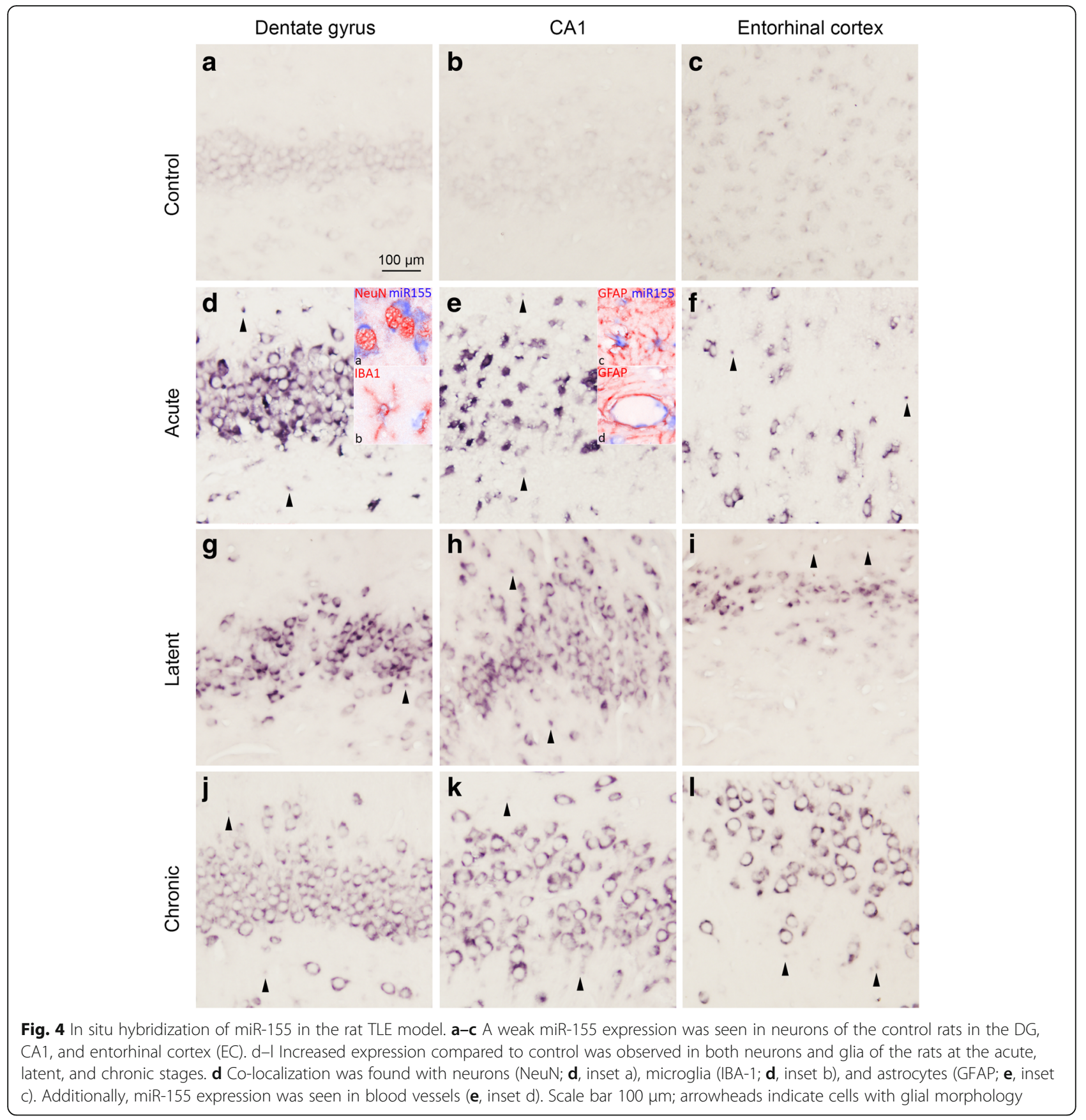

breakdown (through the proteolysis of laminin, fibronectin, and type IV collagen) [33], which can contribute to epileptogenesis.

\section{Increased expression of miR-155 in TLE-HS and during post-SE epileptogenesis in rats}

We found increased expression of miR-155 in the brain of patients with TLE-HS and in the rat TLE model. This supports previous studies, implicating miR-155 in epilepsy $[48,86]$. We have extended these data by characterizing the cellular distribution of miR-155 in both human and rat brain. While miR-155 expression was low in control rats, it was elevated in different sub-regions of the hippocampus and in the PHC throughout epileptogenesis. miR-155 expression was most evident in principal neuronal layers of the hippocampus as well as in glial cells, including astrocytes and microglia. miR-155 has been previously suggested to play a role in modulation of the inflammatory activation in microglia [87-89] and was shown to be upregulated in astrocytes and microglia in response to pro-inflammatory stimuli, such as IL-1 $\beta$, lipopolysaccharide (LPS), interferon gamma (IFN- $\gamma$ ), and 

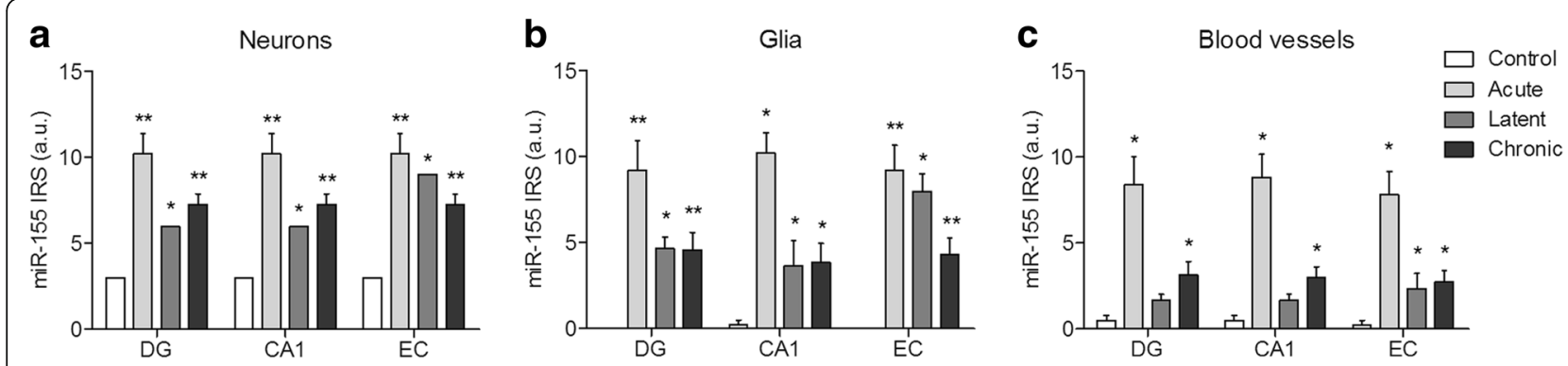

Fig. 5 miR-155 expression in the rat TLE model. A semi-quantitative analysis of miR-155 expression in neurons (a), glia (b), and blood vessels (c) showed that miR-155 was upregulated in these cell types during all phases of epileptogenesis in the dentate gyrus (DG), CA1, and entorhinal cortex (EC). * indicates the comparison to controls for each brain region. ${ }^{*} p<0.05,{ }^{* *} p<0.01,{ }^{* *} p<0.001$, Mann-Whitney $U$ test, error bars depict standard error of the mean

tumor necrosis factor alpha (TNF- $\alpha)[48,49]$. We also observed increased expression of miR-155 in blood vessels in both human and rat hippocampus, implying a role of miR-155 in the BBB dysfunction that occurs in epilepsy. miR-155 was previously found to contribute to the BBB permeability [90]. Moreover, MMP3 knockout mice were demonstrated to have less degradation of tight junction proteins and the basal lamina upon acute pro-inflammatory challenge [91]. Thus, miR-155 was expressed in various cell types in the hippocampus and, similar to MMP3, was increased shortly after an epileptogenic stimulus and elevated throughout epileptogenesis.

\section{miR-155 inhibition as a therapeutic anti-epileptogenic strategy}

The increased expression of MMPs may contribute to the epileptogenic process by contributing to the $\mathrm{BBB}$ dysfunction and exacerbating brain inflammation. Furthermore, MMPs have been proposed as candidate proteases involved in the degradation of the perineuronal nets (PNNs) in epilepsy, and the treatment of rats with an MMP inhibitor doxycycline was demonstrated to prevent PNN degradation in a rat kindling model [92]. MMP3 protein localization has been observed in the perineuronal space [93], and MMP3 substrates include various proteoglycans constituting PNNs, such as aggrecan, neurocan, brevican, versican, phosphacan, and their binding partners, tenascin- $\mathrm{R}$, hyaluronan, and link proteins [94]. This suggests that the inhibition of excessive MMP3 production shortly after a brain insult may alleviate epileptogenic processes such as neurodegeneration and BBB disruption. Indeed, inhibition of MMPs with broad-spectrum MMP inhibitors protected PNNs and had an anti-epileptogenic effect [92]. However, the existing MMP inhibitors have been reported to lack specificity and cause serious side effects [95]. Our data show that inhibition of miR-155 attenuates MMP3 expression under inflammatory conditions in vitro, and therefore, we propose that miR-155 could be a potential therapeutic target, which needs to be further investigated in vivo.

The modulation by inflammation-associated miRNAs has been proposed as a therapeutic approach to treat epilepsy and reduce brain damage. It has been reported that in vivo miR-155 inhibition supports the integrity of endothelial tight junctions, reduces brain tissue damage, improves the functional recovery in animal models after experimental ischemic stroke [96], and reduces seizure frequency in the pilocarpine TLE model [86]. Recently, we have demonstrated that intraventricular administration of miR-146a mimic resulted in a decreased seizure frequency and severity in mice [97] and a similar strategy might be used to study potential disease-modifying effects of miR-155 inhibition. The pharmacological inhibition of

Table 3 In situ reactivity scores of miR-155 in the rat hippocampus and entorhinal cortex

\begin{tabular}{|c|c|c|c|c|c|c|c|c|c|}
\hline \multirow{3}{*}{. } & \multicolumn{3}{|l|}{ DG } & \multicolumn{3}{|l|}{$\mathrm{CA} 1$} & \multicolumn{3}{|l|}{$\mathrm{EC}$} \\
\hline & Neurons & Glia & Vessels & Neurons & Glia & Vessels & Neurons & Glia & Vessels \\
\hline & 3 & 0 & $0.5(0-1)$ & 3 & $0(0-1)$ & $0.5(0-1)$ & 3 & 0 & $0(0-1)$ \\
\hline Acute & $12(6-12)^{* *}$ & $12(4-12)^{* *}$ & $8(4-12)^{*}$ & $12(6-12)^{* *}$ & $12(6-12)^{*}$ & $8(6-12)^{*}$ & $12(6-12)^{* *}$ & $9(4-12)^{* *}$ & $8(4-12)^{*}$ \\
\hline Latent & $6^{*}$ & $4(4-6)^{*}$ & $2(1-2)$ & $6^{*}$ & $4(1-6)^{*}$ & $2(1-2)$ & $9^{*}$ & $9(6-9)^{*}$ & $2(1-4)^{*}$ \\
\hline Chronic & $6(6-9)^{* *}$ & $4(1-9)^{* *}$ & $2(1-6)^{*}$ & $6(6-9)^{* *}$ & $4(1-9)^{*}$ & $3(1-6)^{*}$ & $6(6-9)^{* *}$ & $4(1-9)^{* *}$ & $2(1-6)^{*}$ \\
\hline
\end{tabular}

miR-155 in situ reactivity scores are given as median (minimum-maximum). This score is defined as intensity score (1 no; 2 weak; 3 moderate; 4 strong immunoreactivity) multiplied by relative number score ( 0 no; 1 single to $10 \% ; 211-50 \% ; 3>50 \%) ; D G$, dentate gyrus; $E C$, entorhinal cortex; ${ }^{*} p<0.05$, ** $p<0.01$ 
miR-155 may have a dual benefit: via the reduction of inflammation and by protecting the ECM through the reduction of MMP3 expression.

\section{Conclusions}

Our experiments showed that MMP3 is dynamically regulated by seizures as shown by increased expression in TLE tissue and during different phases of epileptogenesis in the rat TLE model. MMP3 can be induced by the pro-inflammatory cytokine IL-1 $\beta$ and is regulated by miR-155, suggesting a possible strategy to prevent epilepsy via reduction of inflammation.

\section{Additional files}

Additional file 1: Table S1. The list of oligonucleotides. (DOCX $18 \mathrm{~kb}$ )

Additional file 2: Figure S1. MMP expression levels in astrocytic culture. (PDF $93 \mathrm{~kb}$ )

Additional file 3: Figure S2. TaqMan $\mathrm{qPCR}$ analysis of miR-155 expression in astrocytic culture after IL-1 $\beta$ stimulation. (PDF 89 kb)

Additional file 4: Figure S3. MMP expression in astrocytic culture after transfection with antagomiR of miR-155 and miR-146a following IL-1 $\beta$ stimulation. (PDF $100 \mathrm{~kb}$ )

Additional file 5: Figure S4. Densitometrical quantification of miR-155 expression in TLE-HS. (PDF 84 kb)

Additional file 6: Figure S5. Densitometrical quantification of miR-155 expression in the rat TLE model. (PDF $89 \mathrm{~kb}$ )

\begin{abstract}
Abbreviations
AP-1: Activator protein 1; BBB: Blood-brain barrier; C1orf43: Chromosome 1 open reading frame 43; CA1: Cornu Ammonis 1; DG: Dentate gyrus; EC: Entorhinal cortex; ECM: Extracellular matrix; EF1a: Elongation factor 1a; GAPDH: Glyceraldehyde 3-phosphate dehydrogenase; GFAP: Glial fibrillary acidic protein; IFN- $\gamma$ : Interferon gamma; IL-1 $\beta$ : Interleukin-1 $\beta$; IRS: In situ reactivity score; LNA: Locked nucleic acid; LPS: Lipopolysaccharide; miRNA: MicroRNA; MMP: Matrix metalloproteinase; NF-kB: Nuclear factor kappa-light-chain-enhancer of activated B cells; PHC: Parahippocampal cortex; PNN: Perineuronal net; RNU6B: U6B small nuclear RNA; SE: Status epilepticus; TBP: TATA-box-binding protein; TLE-HS: Temporal lobe epilepsy with hippocampal sclerosis; TNF-a: Tumor necrosis factor alpha
\end{abstract}

\section{Acknowledgements}

We thank Anand Lyer for his contribution. We acknowledge the HIS Mouse Facility of the Amsterdam UMC, Amsterdam and the Bloemenhove Clinic (Heemstede, The Netherlands) for providing fetal tissues.

\section{Funding}

The research leading to these results has received funding from the European Union's Seventh Framework Programme (FP7/2007-2013) under grant agreement no. 602102 (EPITARGET; EAvV, JAG, EA), the Dutch Epilepsy Foundation, project number 16-05 (DWMB, EAvV), and the European Union's Horizon 2020 Research and Innovation Programme under the Marie Sklodowska-Curie grant agreement no. 642881 (ECMED; AK, EA).

\section{Availability of data and materials}

All data generated or analyzed during this study are included in this published article (and its supplementary information files).

\section{Authors' contributions}

$A K, D W B, E A V V$, and EA conceived and designed the analysis. JVS and JJA helped with experimental work and methodology. JCB and SI provided human patient tissue. AK and DWB analyzed the data. JG and EAvV contributed to the data interpretation and writing of the manuscript. All authors read, revised, and approved the final manuscript.

\section{Ethics approval and consent to participate}

Human tissue was obtained in accordance with the Declaration of Helsinki and the Amsterdam UMC Research Code provided by the Medical Ethics Committee. The use of animals in this study was approved by the University Animal Welfare committee.

\section{Consent for publication}

Not applicable.

\section{Competing interests}

The authors declare that they have no competing interests.

\section{Publisher's Note}

Springer Nature remains neutral with regard to jurisdictional claims in published maps and institutional affiliations.

\section{Author details}

${ }^{1}$ Department of (Neuro) Pathology, Amsterdam UMC, University of Amsterdam, Meibergdreef 9, 1105 AZ Amsterdam, The Netherlands. ${ }^{2}$ Department of Neurosurgery, Amsterdam UMC, Vrije Universiteit Amsterdam, De Boelelaan 1117, 1081 HV, Amsterdam, The Netherlands. ${ }^{3}$ Swammerdam Institute for Life Sciences, Center for Neuroscience, University of Amsterdam, Science Park 904, 1098 XH, Amsterdam, The Netherlands. ${ }^{4}$ Stichting Epilepsie Instellingen Nederland (SEIN), Heemstede, The Netherlands.

Received: 8 April 2018 Accepted: 2 July 2018

Published online: 21 July 2018

\section{References}

1. Fisher RS, et al. ILAE official report: a practical clinical definition of epilepsy. Epilepsia. 2014;55(4):475-82

2. Hauser WA, Annegers JF, Rocca WA. Descriptive epidemiology of epilepsy: contributions of population-based studies from Rochester, Minnesota. Mayo Clin Proc. 1996;71(6):576-86.

3. Berg AT, et al. Revised terminology and concepts for organization of seizures and epilepsies: report of the ILAE commission on classification and terminology, 2005-2009. Epilepsia. 2010;51(4):676-85.

4. Blumcke I, et al. Histopathological findings in brain tissue obtained during epilepsy surgery. N Engl J Med. 2017:377(17):1648-56.

5. Loscher W. Critical review of current animal models of seizures and epilepsy used in the discovery and development of new antiepileptic drugs. Seizure. 2011:20(5):359-68.

6. Pitkanen A, et al. Epileptogenesis. Cold Spring Harb Perspect Med. 2015 5(10):a022822.

7. Gorter JA, van Vliet EA, Lopes da Silva FH. Which insights have we gained from the kindling and post-status epilepticus models? J Neurosci Methods. 2016;260:96-108.

8. van Vliet EA, et al. Blood-brain barrier leakage may lead to progression of temporal lobe epilepsy. Brain. 2007;130(Pt 2):521-34

9. Gorter JA, van Vliet EA, Aronica E. Status epilepticus, blood-brain barrier disruption, inflammation, and epileptogenesis. Epilepsy Behav. 2015;49:13-6.

10. Nagy $\vee$, et al. Matrix metalloproteinase-9 is required for hippocampal latephase long-term potentiation and memory. J Neurosci. 2006;26(7):1923-34.

11. Ethell IM, Ethell DW. Matrix metalloproteinases in brain development and remodeling: synaptic functions and targets. J Neurosci Res. 2007; 85(13):2813-23.

12. Bajor M, et al. Synaptic cell adhesion molecule-2 and collapsin response mediator protein-2 are novel members of the matrix metalloproteinase-9 degradome. J Neurochem. 2012;122(4):775-88.

13. Jovanov Milosevic $\mathrm{N}$, et al. Neural ECM in laminar organization and connectivity development in healthy and diseased human brain. Prog Brain Res. 2014;214:159-78.

14. Rempe RG, Hartz AM, Bauer B. Matrix metalloproteinases in the brain and blood-brain barrier: versatile breakers and makers. J Cereb Blood Flow Metab. 2016;36(9):1481-507.

15. Srinivasan D, et al. Cell type-specific interleukin-1 beta signaling in the CNS. $J$ Neurosci. 2004;24(29):6482-8.

16. Moynagh PN. The interleukin-1 signalling pathway in astrocytes: a key contributor to inflammation in the brain. J Anat. 2005;207(3):265-9. 
17. Ravizza T, et al. Innate and adaptive immunity during epileptogenesis and spontaneous seizures: evidence from experimental models and human temporal lobe epilepsy. Neurobiol Dis. 2008;29(1):142-60.

18. Xanthos DN, Sandkuhler J. Neurogenic neuroinflammation: inflammatory CNS reactions in response to neuronal activity. Nat Rev Neurosci. 2014; 15(1):43-53

19. Coulter DA, Steinhauser C. Role of astrocytes in epilepsy. Cold Spring Harb Perspect Med. 2015:5(3):a022434.

20. Baldwin KT, Eroglu C. Molecular mechanisms of astrocyte-induced synaptogenesis. Curr Opin Neurobiol. 2017;45:113-20.

21. Thornton $P$, et al. Matrix metalloproteinase- 9 and urokinase plasminogen activator mediate interleukin-1-induced neurotoxicity. Mol Cell Neurosci. 2008;37(1):135-42.

22. Lukasiuk K, Wilczynski GM, Kaczmarek L. Extracellular proteases in epilepsy. Epilepsy Res. 2011:96(3):191-206.

23. Li S, et al. Increased expression of matrix metalloproteinase 9 in cortical lesions from patients with focal cortical dysplasia type IIb and tuberous sclerosis complex. Brain Res. 2012;1453:46-55.

24. Konopka A, et al. Matrix metalloproteinase-9 (MMP-9) in human intractable epilepsy caused by focal cortical dysplasia. Epilepsy Res. 2013;104(1-2):45-58.

25. Quirico-Santos T, et al. Increased metalloprotease activity in the epileptogenic lesion-lobectomy reduces metalloprotease activity and urokinase-type uPAR circulating levels. Brain Res. 2013;1538:172-81.

26. Gorter JA, et al. Dynamic changes of proteases and protease inhibitors revealed by microarray analysis in CA3 and entorhinal cortex during epileptogenesis in the rat. Epilepsia. 2007;48(Suppl 5):53-64

27. Vafadari B, Salamian A, Kaczmarek L. MMP-9 in translation: from molecule to brain physiology, pathology, and therapy. J Neurochem. 2016;139 Suppl 2:91-114.

28. Yoshiyama $Y$, Asahina $M$, Hattori T. Selective distribution of matrix metalloproteinase-3 (MMP-3) in Alzheimer's disease brain. Acta Neuropathol. 2000;99(2):91-5.

29. Cunningham LA, Wetzel M, Rosenberg GA. Multiple roles for MMPs and TIMPs in cerebral ischemia. Glia. 2005:50(4):329-39.

30. Choi DH, et al. A novel intracellular role of matrix metalloproteinase-3 during apoptosis of dopaminergic cells. J Neurochem. 2008;106(1):405-15.

31. Kim EM, et al. Matrix metalloproteinase-3 is increased and participates in neuronal apoptotic signaling downstream of caspase-12 during endoplasmic reticulum stress. J Biol Chem. 2010;285(22):16444-52.

32. Van Hove I, et al. Matrix metalloproteinase-3 in the central nervous system: a look on the bright side. J Neurochem. 2012;123(2):203-16.

33. Kim EM, Hwang $\mathrm{O}$. Role of matrix metalloproteinase-3 in neurodegeneration. J Neurochem. 2011;116(1):22-32.

34. Penkowa $\mathrm{M}$, et al. Metallothionein reduces central nervous system inflammation, neurodegeneration, and cell death following kainic acidinduced epileptic seizures. J Neurosci Res. 2005;79(4):522-34.

35. Dubey $D$, et al. Increased metalloproteinase activity in the hippocampus following status epilepticus. Epilepsy Res. 2017;132:50-8.

36. Lee $R C$, Feinbaum $R L$, Ambros $V$. The $C$. elegans heterochronic gene lin-4 encodes small RNAs with antisense complementarity to lin-14. Cell. 1993;75(5):843-54

37. Ambros $V$. The functions of animal microRNAs. Nature. 2004;431(7006):350-5.

38. Bartel DP. MicroRNAs: genomics, biogenesis, mechanism, and function. Cell. 2004;116(2):281-97.

39. Sonkoly E, Stahle M, Pivarcsi A. MicroRNAs and immunity: novel players in the regulation of normal immune function and inflammation. Semin Cancer Biol. 2008;18(2):131-40

40. Quinn SR, O'Neill LA. A trio of microRNAs that control Toll-like receptor signalling. Int Immunol. 2011;23(7):421-5.

41. Henshall DC. MicroRNA and epilepsy: profiling, functions and potentia clinical applications. Curr Opin Neurol. 2014;27(2):199-205.

42. Cattani AA, et al. Involvement of microRNAs in epileptogenesis. Epilepsia. 2016;57(7):1015-26.

43. Taganov KD, et al. NF-kappaB-dependent induction of microRNA miR-146, an inhibitor targeted to signaling proteins of innate immune responses. Proc Natl Acad Sci U S A. 2006;103(33):12481-6.

44. Aronica $E$, et al. Expression pattern of miR-146a, an inflammation-associated microRNA, in experimental and human temporal lobe epilepsy. Eur J Neurosci. 2010;31(6):1100-7.

45. Iyer A, et al. MicroRNA-146a: a key regulator of astrocyte-mediated inflammatory response. PLoS One. 2012;7(9):e44789.
46. Faraoni I, et al. miR-155 gene: a typical multifunctional microRNA. Biochim Biophys Acta. 2009;1792(6):497-505.

47. Kong H, et al. The effect of miR-132, miR-146a, and miR-155 on MRP8/TLR4induced astrocyte-related inflammation. J Mol Neurosci. 2015;57(1):28-37.

48. Ashhab MU, et al. Expressions of tumor necrosis factor alpha and microRNA-155 in immature rat model of status epilepticus and children with mesial temporal lobe epilepsy. J Mol Neurosci. 2013;51(3):950-8.

49. van Scheppingen J, et al. Expression of microRNAs miR21, miR146a, and miR155 in tuberous sclerosis complex cortical tubers and their regulation in human astrocytes and SEGA-derived cell cultures. Glia. 2016;64(6):1066-82.

50. Stanczyk J, et al. Altered expression of MicroRNA in synovial fibroblasts and synovial tissue in rheumatoid arthritis. Arthritis Rheum. 2008;58(4):1001-9.

51. Long $L$, et al. Upregulated microRNA-155 expression in peripheral blood mononuclear cells and fibroblast-like synoviocytes in rheumatoid arthritis. Clin Dev Immunol. 2013:2013:296139.

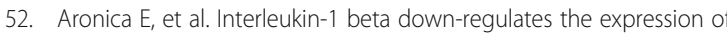
metabotropic glutamate receptor 5 in cultured human astrocytes. J Neuroimmunol. 2005;160(1-2):188-94.

53. Blumcke I, et al. International consensus classification of hippocampal sclerosis in temporal lobe epilepsy: a task force report from the ILAE commission on diagnostic methods. Epilepsia. 2013;54(7):1315-29.

54. Gorter JA, et al. Potential new antiepileptogenic targets indicated by microarray analysis in a rat model for temporal lobe epilepsy. J Neurosci. 2006:26(43):11083-110.

55. Gorter JA, et al. Progression of spontaneous seizures after status epilepticus is associated with mossy fibre sprouting and extensive bilateral loss of hilar parvalbumin and somatostatin-immunoreactive neurons. Eur J Neurosci. 2001;13(4):657-69.

56. Broekaart DWM, et al. Increased expression of (immuno)proteasome subunits during epileptogenesis is attenuated by inhibition of the mammalian target of rapamycin pathway. Epilepsia. 2017;58(8):1462-72.

57. Ramakers C, et al. Assumption-free analysis of quantitative real-time polymerase chain reaction (PCR) data. Neurosci Lett. 2003;339(1):62-6.

58. Ruijter JM, et al. Amplification efficiency: linking baseline and bias in the analysis of quantitative PCR data. Nucleic Acids Res. 2009;37(6):e45.

59. Smith PK, et al. Measurement of protein using bicinchoninic acid. Anal Biochem. 1985;150(1):76-85

60. Delany AM, Brinckerhoff CE. Post-transcriptional regulation of collagenase and stromelysin gene expression by epidermal growth factor and dexamethasone in cultured human fibroblasts. J Cell Biochem. 1992;50(4):400-10.

61. Kirstein M, S.L., Quiñones S, Moscat J, Diaz-Meco MT, Saus J Cross-talk between different enhancer elements during mitogenic induction of the human stromelysin-1 gene. J Biol Chem, 1996. 271(30): p. 18231-18236.

62. Witek-Zawada B, Koj A. Regulation of expression of stromyelysin-1 by proinflammatory cytokines in mouse brain astrocytes. J Physiol Pharmacol. 2003;54(4):489-96

63. Crocker SJ, et al. Cell and agonist-specific regulation of genes for matrix metalloproteinases and their tissue inhibitors by primary glial cells. J Neurochem. 2006:98(3):812-23.

64. Vincenti MP. The matrix metalloproteinase (MMP) and tissue inhibitor of metalloproteinase (TIMP) genes. Transcriptional and posttranscriptional regulation, signal transduction and cell-type-specific expression. Methods Mol Biol. 2001:151:121-48.

65. Moon SK, Cha BY, Kim CH. ERK1/2 mediates TNF-alpha-induced matrix metalloproteinase-9 expression in human vascular smooth muscle cells via the regulation of NF-kappaB and AP-1: involvement of the ras dependent pathway. J Cell Physiol. 2004;198(3):417-27.

66. Ameyar M, Wisniewska M, Weitzman JB. A role for AP-1 in apoptosis: the case for and against. Biochimie. 2003;85(8):747-52.

67. Barkett M, Gilmore TD. Control of apoptosis by Rel/NF-kappaB transcription factors. Oncogene. 1999;18(49):6910-24.

68. Ma X, et al. MicroRNAs in NF-kappaB signaling. J Mol Cell Biol. 2011; 3(3):159-66.

69. O'Connell RM, et al. MicroRNA-155 is induced during the macrophage inflammatory response. Proc Natl Acad Sci U S A. 2007;104(5):1604-9.

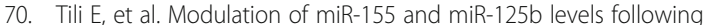
lipopolysaccharide/TNF-alpha stimulation and their possible roles in regulating the response to endotoxin shock. J Immunol. 2007:179(8):5082-9.

71. Ceppi M, et al. MicroRNA-155 modulates the interleukin-1 signaling pathway in activated human monocyte-derived dendritic cells. Proc Nat Acad Sci U S A. 2009;106(8):2735-40. 
72. Pagenstecher A, et al. Differential expression of matrix metalloproteinase and tissue inhibitor of matrix metalloproteinase genes in the mouse central nervous system in normal and inflammatory states. Am J Pathol. 1998;152(3):729-41.

73. Rosenberg GA, et al. Immunohistochemistry of matrix metalloproteinases in reperfusion injury to rat brain: activation of MMP-9 linked to stromelysin-1 and microglia in cell cultures. Brain Res. 2001;893(1-2):104-12.

74. Ulrich $\mathrm{R}$, et al. Matrix metalloproteinases and their inhibitors in the developing mouse brain and spinal cord: a reverse transcription quantitative polymerase chain reaction study. Dev Neurosci. 2005;27(6):408-18.

75. Falo MC, et al. Matrix metalloproteinase-3 expression profile differentiates adaptive and maladaptive synaptic plasticity induced by traumatic brain injury. J Neurosci Res. 2006;84(4):768-81.

76. Becker AJ, et al. Correlated stage- and subfield-associated hippocampal gene expression patterns in experimental and human temporal lobe epilepsy. Eur J Neurosci. 2003;18(10):2792-802.

77. van Vliet EA, Aronica E, Gorter JA. Role of blood-brain barrier in temporal lobe epilepsy and pharmacoresistance. Neuroscience. 2014;277:455-73.

78. Lukasiuk K, Kontula L, Pitkanen A. cDNA profiling of epileptogenesis in the rat brain. Eur J Neurosci. 2003;17(2):271-9.

79. Vezzani A, et al. Epilepsy and brain inflammation. Exp Neurol. 2013;244:11-21.

80. Nairismagi J, et al. Progression of brain damage after status epilepticus and its association with epileptogenesis: a quantitative MRI study in a rat model of temporal lobe epilepsy. Epilepsia. 2004;45(9):1024-34.

81. De Keyser J, Mostert JP, Koch MW. Dysfunctional astrocytes as key players in the pathogenesis of central nervous system disorders. J Neurol Sci. 2008;267(1-2):3-16.

82. Seifert G, Schilling K, Steinhauser C. Astrocyte dysfunction in neurological disorders: a molecular perspective. Nat Rev Neurosci. 2006;7(3):194-206.

83. Carpentier PA, et al. Differential activation of astrocytes by innate and adaptive immune stimuli. Glia. 2005;49(3):360-74.

84. Dong Y, Benveniste EN. Immune function of astrocytes. Glia. 2001;36(2):180-90.

85. Vezzani $A$, et al. Glia as a source of cytokines: implications for neuronal excitability and survival. Epilepsia. 2008;49(Suppl 2):24-32.

86. Huang LG, Zou J, Lu QC. Silencing rno-miR-155-5p in rat temporal lobe epilepsy model reduces pathophysiological features and cell apoptosis by activating Sestrin-3. Brain Res. 2018;1689:109-122.

87. Pareek S, et al. MiR-155 induction in microglial cells suppresses Japanese encephalitis virus replication and negatively modulates innate immune responses. J Neuroinflammation. 2014;11:97.

88. Ponomarev ED, Veremeyko T, Weiner HL. MicroRNAs are universal regulators of differentiation, activation, and polarization of microglia and macrophages in normal and diseased CNS. Glia. 2013;61(1):91-103.

89. Su W, et al. The p53 transcription factor modulates microglia behavior through microRNA-dependent regulation of c-Maf. J Immunol. 2014;192(1):358-66.

90. Lopez-Ramirez MA, et al. MicroRNA-155 negatively affects blood-brain barrier function during neuroinflammation. FASEB J. 2014;28(6):2551-65.

91. Gurney KJ, Estrada EY, Rosenberg GA. Blood-brain barrier disruption by stromelysin-1 facilitates neutrophil infiltration in neuroinflammation. Neurobiol Dis. 2006;23(1):87-96

92. Pollock E, et al. Metalloproteinase inhibition prevents inhibitory synapse reorganization and seizure genesis. Neurobiol Dis. 2014;70:21-31.

93. Baig $S$, Kehoe PG, Love S. MMP-2, -3 and -9 levels and activity are not related to Abeta load in the frontal cortex in Alzheimer's disease. Neuropathol Appl Neurobiol. 2008;34(2):205-15.

94. Muir EM, et al. Matrix metalloproteases and their inhibitors are produced by overlapping populations of activated astrocytes. Brain Res Mol Brain Res. 2002:100(1-2):103-17.

95. Vandenbroucke RE, Libert C. Is there new hope for therapeutic matrix metalloproteinase inhibition? Nat Rev Drug Discov. 2014:13(12):904-27.

96. Caballero-Garrido $\mathrm{E}$, et al. In vivo inhibition of miR-155 promotes recovery after experimental mouse stroke. J Neurosci. 2015;35(36):12446-64.

97. Iori V, Aronica E, Vezzani A. Epigenetic control of epileptogenesis by miR146a. Oncotarget. 2017:8(28):45040-1.

\section{Ready to submit your research? Choose BMC and benefit from:}

- fast, convenient online submission

- thorough peer review by experienced researchers in your field

- rapid publication on acceptance

- support for research data, including large and complex data types

- gold Open Access which fosters wider collaboration and increased citations

- maximum visibility for your research: over $100 \mathrm{M}$ website views per year

At BMC, research is always in progress.

Learn more biomedcentral.com/submissions 